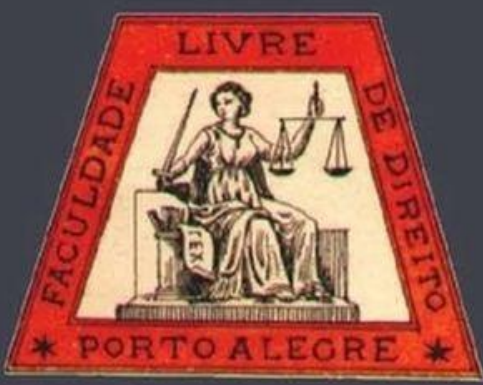

O direito à saúde em Portugal no período da crise

The right to health in Portugal in the period of crisis

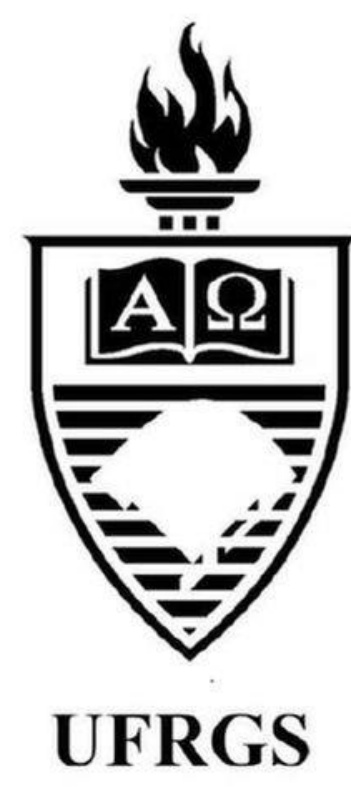

Yuran Quintão Castro

Universidade Federal de Juiz de Fora

Waleska Marcy Rosa

Universidade Federal de Juiz de Fora 


\title{
O direito à saúde em Portugal no período da crise ${ }^{1}$
}

\author{
The right to health in Portugal in the period of crisis
}

Yuran Quintão Castro*

Waleska Marcy Rosa**

\section{REFERÊNCIA}

CASTRO, Yuran Quintão; ROSA, Waleska Marcy. O direito à saúde em Portugal no período da crise. Revista da Faculdade de Direito da UFRGS, Porto Alegre, n. 39, p. 134-151, dez. 2018.

\section{RESUMO}

Este trabalho objetivou analisar, de maneira breve, o Sistema de Saúde em Portugal, devido ao fato de esse país encontrar-se inserido em um contexto de crise econômica, o que, por sua vez, compromete, a prestação de direitos sociais pelo Estado.Para tal intento, foram utilizados os ensinamentos do professor Jorge Reis Novaes acerca da conceituação de direitos sociais, bem como a maneira como esses direitos são tratados, adstritos ao contexto de crise econômica. Além disso, foram consultados artigos jurídicos, publicados em periódicos, que tratam da temática do financiamento do Sistema de Saúde português como um todo,outrossim, a maneira como se dão os gastos do Estado para a garantia do direito à vida..Notou-se que o legislador constituinte evidenciou o Sistema Nacional de Saúde (SNS) como o eixo principal de prestação de serviços públicos de saúde em Portugal. Observou-se que existem algumas maneiras pelas quais o âmbito de prestação de serviços básicos à população é custeado, como as denominadas taxas moderadoras, pagas no próprio hospital, ou em outro local de atendimento público, pelo usuário do serviço, de acordo com o caso concreto. Por fim, o Estado Português, mesmo diante da crise econômica, procurou manter a prestação de saúde de maneira a atender a população de maneira geral e, para isso, adotou medidas como o reajuste das denominadas taxas moderadoras, bem como a realocação de hospitais, concentrando as funções concernentes à saúde em regiões estratégicas, retirando-as de outras áreas.

\section{PALAVRAS-CHAVE}

Direito comparado. Sistema de Saúde. Direito à saúde. Serviço público.

\section{ABSTRACT}

This study aimed to analyze, briefly, the Health System in Portugal, due to the fact that this country is inserted in a context of economic crisis, which, in turn, compromises, the provision of social rights by the State. For this purpose, Professor Jorge Reis Novaes' teaching about the conceptualization of social rights was used, as well as the way in which these rights are treated, attached to the context of economic crisis. In addition, we consulted legal articles, published in periodicals, which deal with the financing of the Portuguese Health System as a whole, as well as the way in which State expenditures are used to guarantee the right to life that the constituent legislator evidenced the National Health System (SNS) as the main axis for the provision of public health services in Portugal. It was observed that there are some ways in which the scope of basic services for the population is funded, such as the so-called fee-for-service fees paid in the hospital itself, or in another public service location, by the service user, according to the case concrete. Finally, despite the economic crisis, the Portuguese State sought to maintain health care in a manner that served the population in general and, for this purpose, adopted measures such as the readjustment of the so-called moderating rates, as well as the relocation of hospitals, concentrating health-related functions in strategic regions, removing them from other areas.

\section{KEYWORDS}

Comparative Law. Health System. Right to health. Public Service.

\footnotetext{
${ }^{1}$ Este trabalho foi desenvolvido no âmbito do Projeto de Pesquisa Crise e direitos sociais: uma análise da jurisprudência da crise em Portugal e as possibilidades de sua aplicação no Brasil, executado de agosto de 2016 a julho de 2017, com financiamento da Universidade Federal de Juiz de Fora (UFJF), na modalidade de bolsas de iniciação científica.

* Graduado em Direito pela Universidade Federal de Juiz de Fora.

** Professora de Direito Constitucional da Universidade Federal de Juiz de Fora. Doutora em Direito pela Universidade Gama Filho. Mestre em Direito pela UERJ.
} 


\section{SUMÁRIO}

Introdução. 1. Direito à saúde como direito fundamental. 1.1. Disposição constitucional sobre o direito à saúde. 1.2. Descrição do sistema de saúde português. 1.3. Sistema Nacional de Saúde como eixo principal da saúde pública em Portugal. 2. O sistema de saúde português no contexto da crise. 2.1. Financiamento do Sistema Nacional de Saúde português. 3. Decretos-lei sobre o sistema de saúde português. Conclusão. Referências.

\section{INTRODUÇ̃̃̃O}

O presente trabalho teve por objetivo descrever o sistema de saúde em Portugal, uma vez que este país, até o presente momento, sofre consequências da crise econômica mundial iniciada em 2008, nos Estados Unidos. Assim, os estudos para a elaboração deste artigo concentraram-se na investigação de decretos-lei editados pelo Governo de Portugal que versavam sobre o âmbito das prestações de saúde cabíveis a este ente, entre os anos de 2008 e de 2017.

Dessa forma, em um primeiro momento, observou-se que o Governo português, com o intuito de diminuir as consequências para a economia nacional, implementou medidas que visavam à redução dos gastos públicos em áreas abarcadas pelos direitos sociais que, por usa vez, dependem do dispêndio financeiro da Administração Pública para serem efetivados.

Diante disso, este artigo teve por objetivo investigar a possibilidade de ter ocorrido reduções dos gastos públicos em relação às prestações de saúde pública no período de crise econômica investigado. Assim, utilizou-se como referencial a proposta teórica do professor português Jorge Reis Novaes acerca dos denominados direitos sociais e como eles encontram-se dispostos na Constituição portuguesa.

Delimitou-se como temática deste trabalho a descrição do sistema de saúde em Portugal, em uma perspectiva exploratória. Com isso, o direito à saúde foi sempre o liame pelo qual desenvolveuse a presente pesquisa, uma vez que este é um dos principais direitos sociais a serem salvaguardados pelas constituições, já que integra o conjunto do denominado mínimo existencial, formado pelos principais direitos que garantirão ao indivíduo o respeito à denominada dignidade da pessoa humana. Com isso, o direito à saúde deve ser garantido para que não somente o texto constitucional possa ser respeitado, mas também para que a população receba as prestações de saúde necessárias para a garantia do respeito do indivíduo como ser humano.

Para se atingir o objetivo acima proposto, foi realizada revisão de literatura de caráter exploratório acerca do tema, bem como, para que fosse verificado o questionamento inicial no caso concreto, realizou-se também pesquisa na legislação portuguesa, analisando, com isso, disposições infra-constitucionais que abarcam o sistema de saúde. Além disso, foram realizados estudos de caso sobre dois decretos-lei, DecretoLei $n^{\circ} 69$ (PORTUGAL, 2013) e Decreto-Lei $n^{\circ}$ 113 (PORTUGAL, 2011), a fim de verificar, diante da realidade fática, como está sendo o tratamento do Estado português acerca das prestações no âmbito da saúde pública.

Este trabalho visa descrever, de um modo inicial, como é a realidade das políticas públicas no setor de saúde adotadas pelo Governo português para garantir à população as prestações necessárias à efetivação da dignidade da pessoa humana, além do respeito aos ditames constitucionalmente previstos. Pretende-se, desse modo, por meio da descrição do cenário português referente ao objeto de pesquisa apresentado, contribuir para as discussões acerca do respeito às garantias das prestações em saúde pública em um contexto de crise econômica.

Assim, na primeira seção, objetivou-se evidenciar algumas características do direito à saúde. Logo em seguida, descreveu-se a maneira 
como tal direito é encontrado na Constituição portuguesa. Posteriormente, o trabalho expôs acerca do sistema de saúde português, evidenciando suas principais características. Diante disso, na abordagem subsequente, abordou-se acerca do principal programa de assistência social que compõe o sistema de saúde, qual seja, o Sistema Nacional de Saúde.

Na segunda seção deste artigo, optou-se por enfatizar o contexto de crise e a relação deste contexto com o as prestações de saúde pública adotadas pelo Governo português. Em seguida, relatou-se sobre o modo de financiamento do Sistema Nacional de Saúde. Por fim, com o intuito de trazer evidências fáticas em concreto, este trabalho estudou dois decretos-lei editados pelo Governo de Portugal no contexto da crise econômica que tratam sobre as prestações de saúde pública assumidas pelo Estado.

\section{DIREITO À SAÚDE COMO DIREITO FUNDAMENTAL}

As revoluções sociais do século $\mathrm{XX}$, tendo como principal expoente a Revolução Russa de 1917, fizeram com que se desenvolvesse um ideal de valorização do indivíduo junto ao Estado, reconhecendo-o como detentor de direitos a serem garantidos por este ente (NOVAES, 2010, p. 1718). Sendo assim, as bases do Estado de Bem Estar Social foram se desenvolvendo a partir dessa ótica garantista em que o cidadão é sujeito de direitos a serem prestados pelo Estado, com o intuito de efetivar condições básicas de existência. Este ideal garantista e prestacional representou uma quebra de paradigma, uma vez que a ideologia até então dominante era voltada para o fato de o Estado atuar o mínimo possível na esfera individual de cada cidadão, conferindo as liberdades inerentes a cada um (NOVAES, 2010, p. 20). Dessa forma, para o Estado, representava uma contenção de gastos, devido ao fato de tal esfera de direito não necessitar de grande despendimento financeiro para ser efetivada, o que é diferente da ideologia de um Estado Social, já que, tradicionalmente, o rol de garantias concernentes aos cidadãos necessita de maiores gastos do Governo em prol da efetivação dos elementos de sobrevivência básicos a cada indivíduo.

Nessa ótica de desenvolvimento políticosocial pelo qual perpassou a sociedade europeia de maneira geral, os Governos, representantes da população, portanto, meros reflexos dos acontecimentos que ocorrem junto ao seio social, começaram a elaborar as constituições e as leis de cada país englobando esta ideia que ganhava cada vez mais força. Tal ideologia encampava os denominados direitos sociais e democráticos, bem como os até então predominantes direitos de liberdade (NOVAES, 2010, p. 20). Nesse sentido, pode-se ressaltar que as políticas de governo passaram por algumas mudanças, pois, conforme foi evidenciado acima, essas novas garantias, denominadas de direitos sociais, apresentam como características básicas a necessidade de acesso do cidadão a bens de natureza econômica, social e cultural, indispensáveis à vida digna; bem como possuem como particularidade o fato de serem bens escassos e custosos, a que os indivíduos somente conseguem ter acesso se dispuserem, eles próprios, por si ou pelas instituições em que se integrem, de suficientes recursos financeiros ou se obtiverem ajuda ou as correspondentes prestações por parte do Estado (NOVAES, 2010, p. 41).

Sendo assim, os direitos sociais, especificamente, possuem como elemento básico o fato de serem conferidos pelo Estado por meio de prestações destinadas a promover o acesso a tais direitos a quem não dispõe de recurso próprio para os alcançar (NOVAES, 2010, p. 42). Portanto, os direitos sociais representam o acesso a um mínimo existencial, que engloba os direitos à saúde, à habitação, à segurança social, ao 
trabalho e à educação, por exemplo (NOVAES, 2010, p. 40-41).

A partir desse contexto, pode-se verificar que os direitos sociais são de grande importância para a manutenção da dignidade da pessoa humana do indivíduo socialmente inserido. Dessa forma, adquirem a fundamentalidade na prestação a partir do momento em que são positivados pelos denominados Estados de Direito, ou seja, por aqueles Estados que adotam a normatividade jurídica como base para a conformação das relações sociais.

Com efeito, o direito à saúde pertence ao rol, não taxativo, dos direitos que são necessários para garantir as mínimas condições de existência do indivíduo em sociedade. Assim, conforme foi demonstrado, tal direito também faz parte de todo o processo de conquista social realizado por meio de revoluções sociais do século XX, em que a Revolução Russa é o principal expoente. Ademais, o caráter de direito fundamental que ele possui deve-se ao fato de ser multifacetado, uma vez que atua não somente sobre a esfera da vida, mas também sobre o setor econômico, social e político, por exemplo.

$\mathrm{O}$ fato de o direito à saúde ser positivado por uma constituição ou por um ordenamento jurídico, de maneira geral, somente tem o escopo de demonstrar essa grande importância para a manutenção da dignidade da pessoa humana do indivíduo, bem como garantir da melhor maneira possível a coexistência dos sujeitos socialmente inseridos. Logo, a partir do momento em que o Estado positiva tais normas, torna-se obrigado a efetivá-las da melhor e na maior maneira possível, de acordo com os demais deveres a que esteja incumbido.

\subsection{Disposição constitucional sobre o direito à saúde}

Conforme verificado, o direito à saúde é um direito que possui grande preponderância frente aos demais direitos a serem salvaguardados pelo ordenamento jurídico português, uma vez que tem como objetivo principal tutelar a vida de cada indivíduo destinatário das normatizações portuguesas.

Diante disso, o legislador originário elaborou a Constituição de Portugal, datada do ano de 1976, trazendo no art. 64 (PORTUGAL, 1976) as disposições concernentes ao tratamento do direito fundamental à saúde no território português. É necessário evidenciar que, inicialmente, esse direito seria garantido, principalmente, pelo Estado português, por meio do denominado Sistema Nacional de Saúde (ao qual será dedicada seção específica) que, por sua vez, possuiria como princípios basilares a universalidade, a gratuidade e a generalidade nos distintos tratamentos e prevenções de doenças (CARVALHO, 2013, p. 9).

Contudo, no ano de 1989, na segunda revisão constitucional (Lei Constitucional $\mathrm{n}^{\circ}$ 1/89), alterou-se o art. $64^{\circ}, n^{\circ} 2$, alínea "a" da Constituição (PORTUGAL, 1976), modificando o caráter gratuito do Sistema Nacional de Saúde, para um programa tendencialmente gratuito (CARVALHO, 2013, p. 10), ou seja, a partir de então, foi constitucional a cobrança de determinada taxa mediante a realização de algum serviço público relacionado à garantia do direito à saúde em Portugal.

Assim, este mesmo artigo prevê que a proteção da saúde é um dever não somente do Estado, mas também da sociedade, de maneira geral, além do fato de ser também um direito conferido a todos os cidadãos (CRISÓSTOMO, 2016, p. 33). Ademais, deve-se ressaltar que a realização da proteção à saúde não se resume somente na criação e efetivação do programa do Sistema Nacional de Saúde, mas também existem outras políticas públicas elaboradas pelo Estado a fim de permitir uma maior e melhor garantia deste direito junto à sociedade (CRISÓSTOMO, 2016, p. 34), conforme é evidenciado pelo $\mathrm{n}^{\circ} 2$, alínea 
"b", do artigo 64 (PORTUGAL, 1976), sob análise.

Ainda acerca dos deveres de prioridade do Estado português na proteção à saúde, a Constituição prevê no $\mathrm{n}^{\mathrm{o}} 3$, deste mesmo artigo, um rol de atribuições, quais sejam: garantir o acesso de todos a cuidados de saúde preventiva, curativos e de reabilitação; equidade de acesso; orientar a ação para o financiamento público dos custos em saúde; regular, supervisionar e articular a prestação pública e privada (eficiência e qualidade); regular e supervisionar as atividades relacionadas com medicamentos, meios complementares de diagnóstico e terapêutica e outros produtos de saúde; estabelecer políticas de prevenção e tratamento de toxicodependência (CRISÓSTOMO, 2016, p. 34).

Por fim, o dispositivo constitucional aqui analisado ainda dispõe sobre algumas diretivas no $\mathrm{n}^{\circ} 4$ quanto à maneira como será operacionalizada a gestão do Serviço Nacional de Saúde, determinando, com isso, que tal gestão seja descentralizada e participativa. Dessa forma, o legislador tem o escopo de fazer com que a sociedade participe ainda mais nas políticas de saúde pública, já que assegura um caráter democrático na participação do principal programa de assistência à população nacional e estrangeira (caráter universal e geral). Além disso, pode-se interpretar que esta abertura para a participação popular tem o objetivo de atender outra disposição constitucional prevista neste mesmo artigo, a de que cabe também à sociedade o dever de promover a proteção à saúde. Sendo assim, o legislador objetivou respeitar uma norma constitucional, bem como conferir grande importância à população nas políticas de saúde pública, demonstrando que, com a participação popular, pode haver maior eficácia nos programas de assistência do Sistema Nacional de Saúde.

Com efeito, observa-se que o Estado português é regido por uma constituição, especialmente no art. 64 (PORTUGAL, 1976), diretiva, uma vez que neste dispositivo há uma série de deveres elencados pelo legislador, aos quais o Estado português está incumbido de promover, sob pena de violar gravemente um direito fundamental assegurado aos cidadãos nacional e estrangeiro, situados em território português.

Há também que se analisar o fato de nesta mesma norma constitucional haver a expressa necessidade de a sociedade atuar ao lado do Governo de Portugal para, juntos, promoverem uma proteção à saúde que possa ser, na maior medida possível, eficiente e eficaz a todos os usuários de tais serviços. Outrossim, ressalta-se a intenção do legislador de proporcionar esta atuação conjunta para que os programas na área da saúde a serem criados consigam atender às mais distintas demandas, pertencentes a diferentes grupos sociais.

\subsection{Descrição do sistema de saúde português}

O sistema de saúde em Portugal, conforme demonstrado anteriormente, possui como eixo principal, o Sistema de Saúde Nacional (SNS), uma vez que este é o programa de saúde constitucionalmente previsto para atender às demandas de saúde pública em Portugal. Além disso, também foi demonstrado que este programa possui, como um de seus princípios, o fato de ser tendencialmente gratuito (alteração realizada pela Lei Constitucional $n^{\circ} 1$ - PORTUGAL, 1989), com isso, dependendo da demanda a ser pleiteada pelo indivíduo, far-se-á determinado despendimento financeiro por este usuário do sistema público de saúde.

Desse modo, a autorização da cobrança de determinada quantia pela utilização do sistema de saúde respeita o denominado princípio da solidariedade ou da redistribuição. Este princípio permite a cobrança de acordo com o rendimento auferido pelo usuário, bem como conforme as 
necessidades por ele pleiteadas (SOUSA, 2009, p. 888-889).

Além disso, a saúde também é financiada por outras vias que serão apresentadas posteriormente. Pode-se, ainda, evidenciar a existência de outro princípio norteador de tais formas de custeio do sistema de saúde, o chamado princípio da previdência. Este princípio tem como característica a necessidade de se pagar determinada quantia para subsidiar o sistema, durante o decurso da vida, com o objetivo de poder receber os cuidados médicos necessários quando estiverem mais idosos e mais suscetíveis a outros tipos de enfermidades, analisa Sousa (2009, p. 889).

Assim, observa-se que também é possível que exista a gratuidade em algumas prestações de serviço, uma vez que existe o pagamento pelos utilizadores na forma de impostos, sendo estes revertidos em investimentos para o setor, com o fulcro de atender, principalmente de maneira gratuita, aqueles indivíduos que não possuem as condições sociofinanceiras, devidamente comprovadas, necessárias para arcar com algum tipo de tratamento custoso e salutar para a garantia da vida.

O sistema de saúde português possui o SNS como o principal programa de atendimento à população nacional, muito em função da expressa previsão constitucional para que o governo crie as ferramentas necessárias, para permitir a existência e manutenção de um serviço de grande importância para a população, já que é por meio dele, principalmente, que o basilar direito fundamental à vida é concretizado. Nesse sentido, o sistema de saúde português é caracterizado como misto, pois possui algumas fontes de financiamento e acesso aos serviços de saúde.

Assim, deve-se destacar que a saúde em Portugal possui o SNS como o principal meio de acesso ao setor de saúde, devido ao seu caráter universal. Porém existem outros subsistemas, de maior participação do capital privado, que também constituem vias de acesso à prestação da saúde. Sendo assim, há o denominado seguro social, representado pelos fundos de saúde de matriz profissional, ou seja, um regime de seguro de saúde especial para determinadas profissões, com cerca de $25 \%$ da população (SERAPIONE; SESMA, 2011, p. 612). Existe também o seguro voluntário, constituído pelo financiamento individual, representado pelos seguros de saúde privados, abarcando cerca de $17 \%$ da população (SERAPIONE; SESMA, 2011, p. 612). Por fim, há a via de pagamento direto dos usuários (BOGANHA; RIBEIRO; PIRES, 2002, p. 8).

Pelo exposto, pode-se inferir que o sistema de saúde português possui certa participação do capital privado em seu orçamento, sendo tal aporte dividido nos denominados seguros de saúde. Observa-se também que o Estado não é o único agente responsável por garantir a prestação da saúde junto à população, pois possui como gasto $64,7 \%$ do montante total dos encargos neste setor (MINISTRO DA SAÚDE, 2017, on line).

Contudo, vem sendo observada certa contenção dos despendimentos financeiros do Governo na área da saúde (BOGANHA; RIBEIRO; PIRES, 2002, p.11), permitindo, pois, que o setor privado aumente, ainda mais, seu poder de influência sobre as políticas públicas empregadas. Desse modo, há um aumento no já desigual acesso aos serviços de saúde essenciais, uma vez que o caráter de ser tendencialmente gratuito torna-se ainda mais preponderante, haja vista essa política de contenção de gastos adotada pelo Governo português em um contexto de crise. Logo, o desenvolvimento da inserção do setor privado em uma área prioritária, como o âmbito da saúde pública, acarreta na redução a "meros simulacros de cidadania" de princípios como o da universalidade e o da gratuidade, pois, perante o poder e a força deste grande setor, tais princípios não coadunam com os interesses difundidos por ele (BOGANHA; RIBEIRO; PIRES, 2002, p.12). 
1.3 Sistema nacional de saúde como eixo principal da saúde pública em Portugal

O Serviço Nacional de Saúde, a despeito de toda a disposição constitucional que versa sobre ele, tem na Lei $n^{\circ} 56$ (PORTUGAL, 1979) o dispositivo infraconstitucional que estabelece a sua criação. Neste diploma, há aquilo que a Constituição prevê como fundamental para nortear o funcionamento de um sistema público de saúde, embasado nos já referidos princípios da universalidade e da generalidade, além de, após a reforma no art. $64^{\circ}$ (PORTUGAL, 1976), assumir um caráter tendencialmente gratuito. Ademais, em relação à maneira como irá operar tamanho programa assistencialista, esse dispositivo legal também reafirma a expressa previsão constitucionalmente trazida de possuir uma gestão de caráter descentralizado, bem como de cunho democrático (CRISÓSTOMO, 2016, p. 37).

Dessa forma, o fato de ser um sistema universal, representa que todos os cidadão portugueses têm o direito de recorrer a ele, logo possui o escopo de abranger $100 \%$ da população nacional. Nesse sentido, o fato de ser geral, objetiva envolver "todos os cuidados integrados de saúde, compreendendo a promoção e vigilância da saúde, a prevenção da doença, o diagnóstico e tratamento dos doentes e a reabilitação médica e social." (CRISÓSTOMO, 2016, p. 44).

Em relação ao fato de ser tendencialmente gratuito, como já foi demonstrado, na promulgação da Constituição (PORTUGAL, 1976), o Sistema Nacional de Saúde deveria ser gratuito a toda população, a fim de abarcar, principalmente, aqueles que não possuem as condições econômicas necessárias para pagar algum plano de saúde particular ou mesmo custear tratamentos por meio do pagamento privado efetuado de maneira direta ao médico que realizasse $\mathrm{o}$ atendimento. Este escopo do legislador baseia-se em um caráter garantista pelo qual a Constituição portuguesa foi criada, uma vez que ela é muito preocupada com a efetivação dos direitos fundamentais (MIRANDA, 2007, on line). Contudo, percebeu-se nos primeiros anos de vigência da Constituição portuguesa que a gratuidade integral nos serviços de saúde prestados, em função serem serviços intrinsecamente custosos, iria sobrecarregar o orçamento do Estado, comprometendo, inclusive, outras políticas públicas que pleiteiem a efetivação de diferentes direitos fundamentais.

Com isso, houve a modificação da orientação constitucional, outrora prolatada para que o cidadão pudesse também, de maneira direta, mesmo que por uma quantia não muito relevante ter acesso aos cuidados de saúde (RAIMUNDO, 2013, p. 144). Então, o SNS passou a ser financiado não somente por recursos oriundos do orçamento do Estado, mas também mediante o pagamento direto dos usuários. Vale ressaltar que, no ano de 1993, mediante o Decreto-Lei $n^{\circ} 11$ (PORTUGAL, 1993), entrou em vigor o Estatuto do SNS, determinando, em seu art. $23^{\circ}$, as distintas formas de financiamento deste sistema, o que ainda será objeto de discussão nesta produção.

Outrossim, a Constituição (PORTUGAL, 1976) trouxe a necessidade do SNS ser descentralizado, bem como possuir cunho democrático junto ao âmbito administrativo, corroborando com o fato da Constituição de 1976 restaurar a legalidade democrática, reafirmando a democracia política de cunho liberal e pluralista (MIRANDA, 2007, on line).

Com efeito, conforme dispõe o Estatuto do SNS (PORTUGAL, 1993), o SNS é organizado por regiões de saúde que, por sua vez, se subdividem em sub-regiões, integradas por áreas de saúde, de acordo com o art. $3^{\circ}$ (PORTUGAL, 1993), atendendo, com isso, o caráter descentralizado em sua administração. Contudo, o Ministro da Saúde tem poder de influência e de 
físcalização sobre essas diferentes formas de administração regionais, uma vez que o Ministro deve nomear o coordenador sub-regional, indicado por um conselho de administração das distintas administrações regionais de saúde (PORTUGAL, 1993). Além disso, por exemplo, cabe também ao Ministro da Saúde elaborar portarias que classifiquem as instituições e os serviços segundo a natureza de suas responsabilidades e o quadro das valências efetivamente exercidas (PORTUGAL, 1993).

Por derradeiro, o caráter democrático é encontrado na existência dos denominados conselhos regionais de saúde e nas comissões concelhias de saúde, órgãos de consulta das administrações regionais de saúde. Já que, conforme dispõe o artigo $8^{\circ}$ (PORTUGAL, 1993), os conselhos serão escolhidos mediante o perfil e a experiência na matéria. Além disso, o artigo $11^{\circ}$ (PORTUGAL, 1993) traz a listagem daqueles que poderão fazer parte das denominadas comissões concelhias de saúde

Das comissões concelhias de saúde fazem parte:

a) Os directores dos hospitais, quando os houver;

b) Os directores dos centros de saúde;

c) Os dirigentes máximos de serviços oficiais de saúde com sede no conselho e não integrados em hospitais ou centros de saúde;

d) Um representante do município;

e) Um representante da misericórdia ou, não a fazendo, de outra instituição particular de solidariedade social, a designar pela União das Instituições Particulares de Solidariedade Social;

f) Um representante dos interesses dos utentes, eleito pela assembleia municipal.

Destarte, observa-se que há a intenção do legislador em garantir a participação de diferentes setores da sociedade ligados direta ou

\footnotetext{
${ }^{2}$ Portugal já começa a demonstrar sinais de crescimento depois do período de crise, uma vez que no primeiro trimestre deste ano apresentou um crescimento de 2,8\% do PIB em relação ao mesmo período de 2016. Este desempenho econômico foi o melhor desde o ano de 2007 (A ECONOMIA., 2017, on line).

Em relação ao continente europeu, foram tomadas algumas iniciativas para que os países integrantes da União Europeia pudessem recuperar suas economias, como por exemplo a
}

indiretamente ao sistema de saúde português, abarcando desde o usuário do sistema, até os representantes dos órgãos diretivos que irão coordenar ações na área de saúde propriamente ditas.

\section{O SISTEMA DE SAÚDE PORTUGUÊS NO CONTEXTO DA CRISE}

A crise econômica que atingiu a União Europeia por volta do ano de 2008 e que até o presente momento acarreta graves consequências ${ }^{2}$ para algumas economias deste importante bloco econômico, possui como causa principal o aumento vertiginoso da dívida pública das economias nacionais (CAUSAS, 2013, on line). Países como Portugal, Espanha, Itália e Grécia foram os principais afetados, tendo, por exemplo, este último contraído uma dívida equivalente a 148,6\% do PIB no ano de 2010 (CAUSAS, 2013, on line).

Portugal, uma das grandes economias atingidas pela crise econômica, chegou a ter 93,3\% de dívidas acima do PIB (CAUSAS, 2013, on line). Dessa forma, o Governo viu-se obrigado a adotar medidas que pudessem não somente retirar o país dessa grave situação econômica, mas também criar políticas que não acarretassem grandes retrações em setores responsáveis pela promoção de direitos sociais de maneira direta.

Diante disso, em 2011, o Governo português assinou
o denominado Memorando de Entendimento,
objetivando amenizar os efeitos desta crise
econômica para o setor de saúde. Assim, adotaram-
se medidas de caráter estrutural, como por exemplo
medidas tendentes à implementação de práticas de
rigor e de transparência nos procedimentos por meio
de um conjunto de instrumentos de monitorização e aplicação de 1,6 bilhões de euros no sistema bancário; criação de uma rede de segurança para os países de tal grupo econômico em dificuldade: o Mecanismo Europeu de Estabilidade; a criação de regras mais estritas, para manter sob controle dívidas e déficit públicos e garantir que os Estados não gastem acima de suas possibilidades (ASSUNTOS, 2017, on line). 
controle da utilização de recursos públicos (ANDRADE, 2016, p. 211).

Ainda segundo a autora, tal memorando também trouxe modificações conjunturais, como por exemplo a contenção e a racionalização de gastos prioritariamente com os recursos humanos, realizando cortes transversais nas remunerações.

Com efeito, observa-se que o Estado português adotou medidas com o fulcro de reduzir os gastos do setor de saúde a ser sustentado pelos cidadãos. Contudo, conforme já foi dito neste trabalho, o setor de saúde é uma área que depende, principalmente, de considerável despendimento financeiro para garantir a eficácia e a eficiência nas prestações a ela cabíveis.

Sendo assim, Portugal não possui as condições econômicas necessárias para garantir a prestação dos serviços de saúde da maneira como está previsto na Constituição (PORTUGAL, 1976), uma vez que o sistema de saúde português é definido como de matriz Beveridgiana, significando, pois, que o governo deve arcar com os cuidados de saúde da população (caráter universal e geral) (RAIMUNDO, 2013, p. 142). Logo, para que haja um equilíbrio nesse complicado contexto, o Estado deve se aliar ainda mais ao capital advindo da iniciativa privada para que não possa ocorrer maiores retrocessos em uma garantia fundamental a todo ser humano, qual seja, a prestação do direito à saúde, conforme os princípios constitucionais elencados.

Desse modo, é fundamental que exista uma definição dos papéis a serem assumidos por cada agente prestador do serviço, sendo ele público ou privado, para que o usuário possa ter a segurança de saber qual é o responsável pela obrigação que ele fez uso. Assim, coadunando com as propostas de Andreia da Costa Andrade (2016, p. 212), deve-se haver uma separação nas funções assumidas pelo Estado como prestador, como financiador e como garantidor dos serviços de saúde prestados à população. Ademais, a maior integração junto a entidades privadas prestadoras de cuidados de saúde, tal qual foi alhures abordado, é mais uma alternativa. Contudo, tal intervenção privada deve ser fiscalizada de maneira ainda mais detida pelo Estado para que não possa ocorrer distorções na aplicabilidade dos princípios norteadores do sistema de saúde (ANDRADE, 2016, p. 212).

Via de regra, cabe ao Governo aumentar e melhorar os sistemas de fiscalização para o sistema de saúde, uma vez que diante dessa proposta há grande aumento no poder de influência de entidades distintas do Sistema Nacional de Saúde (principal programa público do sistema de saúde português). Assim, acarreta alguma consequência ao cidadão que pode ficar ainda mais vulnerável diante de decisões discutíveis quanto ao real intuito prestacional de medidas necessárias para a garantia do direito à saúde à diversidade da população (universalidade).

Logo, é necessário otimizar a regulação nessa possibilidade de aumento da participação do capital privado no setor de saúde. Nesse sentido, conforme elucida Andreia da Costa Andrade (2016), tal abertura acarreta três acontecimentos, quais sejam: a institucionalização das parcerias público-privadas, a denominada empresarialização dos estabelecimentos públicos prestadores de cuidados à saúde e, por fim, um reconhecimento da existência de um mercado privado no setor de saúde.

Nesse sentido, evidencia-se que os investimentos advindos da iniciativa privada assumem um papel de certa preponderância em face daquilo que é gasto pelo Estado para custear as prestações de saúde em consonância com os princípios basilares elencados no artigo $64^{\circ}$ (PORTUGAL, 1976). Dessa forma, o país encontra-se em um dilema, já que há dificuldade em compatibilizar a efetivação do acesso a serviços de saúde à sociedade, com a sustentabilidade econômico-financeira do sistema de saúde (ANDRADE, 2016, p. 217). 
Portanto, o objetivo de melhorar a capacidade do Estado português em estabelecer uma regulamentação mais pormenorizada junto ao sistema de saúde, após o aumento da importância da atuação da iniciativa privada em um âmbito de tamanho destaque, tem o objetivo de permitir o equilíbrio entre a efetivação da garantia do direito fundamental à saúde e a sustentabilidade econômico-financeira do sistema de saúde em Portugal. (ANDRADE, 2016, p. 217).

\subsection{Financiamento do sistema nacional de saúde português}

O Sistema Nacional de Saúde possui como um dos seus princípios constitucionais, o fato de ser um programa de saúde não necessariamente gratuito, apesar de ter como objetivo o atendimento à totalidade da população. Logo, de antemão, analisa-se que os próprios usuários do Sistema custeiam, por meio de um pagamento de determinada contribuição, a assistência de saúde pleiteada (princípio do tendencialmente gratuito). Vale ressaltar que nem todos os usuários deste Sistema têm que realizar determinado pagamento para poderem usufruir dos cuidados de saúde, uma vez que, caso seja comprovada a situação financeira do indivíduo, ele poderá ficar isento da realização do pagamento, quando necessitar do atendimento ou de outro serviço neste setor.

Ademais, o artigo $23^{\circ}$ do Estatuto do SNS elenca os responsáveis para o financiamento deste programa. Dessa forma, cabe ao Estado, principalmente, custear os gastos advindos do atendimento de saúde à população. Além dele, os utilizadores não beneficiários do SNS também arcam com a manutenção deste sistema; bem como os beneficiários, na parte que lhes couber, levando em consideração as suas condições econômicas e sociais. Outros agentes também arcam com esse financiamento, quais sejam, os subsistemas de saúde e todas as entidades e as instituições que, de alguma maneira, estejam ligadas ao SNS (BAGANHA; RIBEIRO; PIRES, 2002, p. 8). Por fim, este mesmo artigo do estatuto menciona que também cabem os encargos aos "responsáveis por infração às regras de funcionamento do sistema ou por uso ilícito dos serviços ou material de saúde" (PORTUGAL, 1993).

Em um contexto de crise econômica, o Estado português tende a diminuir ainda mais, como já foi afirmado, a sua participação no custeio da saúde pública, fazendo com que o princípio do tendencialmente gratuito ganhe ainda mais força frente aos demais, universalidade e generalidade. Com isso, os impostos arrecadados, cada vez mais, tendem a ser destinados a áreas que visam a recuperação da economia nacional, como por exemplo, criando incentivos fiscais para empresas gerarem mais empregos.

A partir disso, observa-se que há, portanto, maior disponibilidade para o setor privado atuar também no custeio do SNS, já que, tal qual foi afirmado neste trabalho, há um aumento na participação da iniciativa privada no oferecimento de serviços relacionados à saúde, devido ao fato de haver uma retração da participação estatal no oferecimento de serviços básicos de saúde, bem como a necessidade de manter estas garantias fundamentais junto à sociedade de maneira geral.

Nesse sentido, os denominados seguros de saúde, um dos exemplos de subsistemas de saúde e também responsáveis pelo custeio do SNS, aumenta o poder de atuação também sobre o setor público de prestação de saúde. Destarte, infere-se que a iniciativa privada ganha ainda mais poder frente ao Estado em um setor básico e primordial para os cidadãos, aumentando-se a vulnerabilidade daqueles que não possuem condições socioeconômicas para custear determinados tratamentos de saúde.

Sendo assim, vê-se que o princípio do tendencialmente gratuito acaba possuindo mais força frente os demais princípios norteadores do 
SNS, quais sejam os princípios da universalidade e da generalidade, devido ao fato de, cada vez mais, haver a diminuição do assistencialismo do Estado perante as classes menos favorecidas da população, já que a área da saúde, por natureza, demanda maior aporte de capital para ser efetivada de acordo com os ditames constitucionais.

Então, diante da situação econômica instável que perpassa Portugal, o Sistema Nacional de Saúde, principal programa de assistência de saúde dentro do Estado português, enfrenta uma diminuição em sua capacidade de abarcar a população nacional como um todo. Dessa forma, a iniciativa privada expande-se perante aquelas áreas em que o SNS não abrange de maneira satisfatória, elevando o seu poder de barganha perante o Governo e suas políticas públicas no setor de saúde, uma vez que além de atender a parte da população que necessita de melhores e mais eficazes serviços de saúde prestados, também auxilia na manutenção do principal programa de assistência de saúde pública elencado pela Constituição Federal (PORTUGAL, 1976).

\section{DECRETOS-LEI SOBRE O SISTEMA DE SAÚDE PORTUGUÊS}

Os decretos-lei são uma das maneiras utilizadas para normatizar determinadas matérias no ordenamento jurídico português. Nessa esteira, de acordo com Canotilho (2003, p. 796), o decreto-lei, de competência do Governo, deve ser aprovado pelo Conselho de Ministro, uma espécie de órgão colegiado do Governo de Portugal, presidido pelo primeiro-ministro, em que têm assento todos os demais ministros do Governo, bem como os secretários de Estado que o primeiro-ministro escolher por convocar.

Ainda de acordo com esta modalidade de regramento, Canotilho (2003, p. 797) também aduz que os decretos-lei podem comportar qualquer tipo de matéria. Por fim, para poderem viger, os decretos-lei, de competência legislativa exclusiva do Governo, devem ser apreciados anteriormente pela Assembleia da República, na qual haverá a análise dos parlamentares sobre o objeto a ser regulamentado (CANOTILHO, 2003, p. 799).

Diante disso, evidencia-se que este modo de criar uma norma tem o objetivo de atender de maneira mais detida determinadas políticas a serem adotadas pelo governo que estiver diante da administração pública do país. Logo, em face de um problema, por exemplo, e de acordo com a política de governo adotada pela administração que estiver no poder, o Conselho de Ministros elaborará alguma medida que, posteriormente, deverá ser aprovada pelo Parlamento, objetivando atender a alguma demanda existente no país.

Assim, a elaboração de um decreto-lei é de iniciativa do Poder Executivo, por isso necessita de haver certo controle pelos demais poderes, a fim de evitar arbitrariedades ou favorecimentos que, por ventura, possam vir a ser tratados em tal regramento. Por isso, faz-se necessário existir a fiscalização da Assembleia da República, para verificar também se aquela matéria tratada, a despeito dos eventuais problemas morais e éticos que ela possa versar, realmente respeita as orientações e as medidas políticas propostas para governar o país, presentes no Programa de Governo anteriormente aprovado por esta mesma casa.

Prosseguindo, a fim de realizar uma breve análise da situação das prestações do direito fundamental à saúde em um contexto de crise, em Portugal, foram selecionados dois decretos-lei que tratam de algumas políticas adotadas pelo Governo para tentar garantir à população a continuidade de serviços essenciais para a preservação da dignidade da pessoa humana e, em última medida, objetivando salvaguardar o direito à vida. 
Sendo assim, o primeiro decreto-lei a ser analisado é o Decreto-Lei $n^{\circ} 69$ (PORTUGAL, 2013), que trata da criação do Centro Hospitalar de Algarve, por fusão do Barlavento Algarvio, com o Hospital de Faro. Assim, diante da leitura dos motivos que levaram o Governo a propor tal medida, observa-se que o XIX Governo Constitucional pretendeu concentrar os serviços de saúde em uma área maior, de fácil localização e com boas vias de acesso, facilitando a nova logística de saúde a ser implementada. Além disso, para realocar os recursos que estavam dissipados em regiões menores para, com isso, diminuir os gastos, bem como ampliar a eficiência das prestações advindas deste planejamento. (PORTUGAL, 2013).

Haja vista o período de crise econômica e austeridade financeira que perpassa o território português, a centralização da gestão de unidades hospitalares é uma medida necessária. Devido a isso, haverá a racionalização e a adequação dos meios, com a redução imediata de recursos, com o intuito de obter, a despeito disso, maior eficácia, eficiência e efetividade na operacionalização dos planejamentos relacionados aos cuidados hospitalares para a região (PORTUGAL, 2013).

Com efeito, observa-se que o Estado português pleiteia não deixar de prestar os serviços necessários ao setor de saúde, a despeito de toda a situação econômica na qual ele se encontra. Com isso, faz uso de políticas públicas que tendem a diminuir os gastos do Governo sem, contudo, acarretar em um déficit grave nas prestações de tais cuidados básicos para a população. Dessa forma, a concentração da gestão hospitalar na região do Algarve tem este escopo, já que é uma área maior em relação às outras nas quais se instalavam os outros hospitais, bem como não é de difícil acesso e ainda dispõe, em tese, de boas condições para proporcionar a instalação de um hospital que possa atender não somente a população local, mas também aquela que não irá mais possuir os serviços hospitalares disponíveis nas anteriores localidades.

Ainda acerca da análise de alguns casos que ilustram a temática abordada neste trabalho, foi analisado outro decreto-lei elaborado com o escopo de respeitar uma política de Governo de contenção de gastos no setor da saúde pública para que o Estado português pudesse, de alguma maneira, sair da situação de grave recessão econômica que se encontrava. Então, o DecretoLei $\mathrm{n}^{\circ} 113$ (PORTUGAL, 2011) foi também selecionado para servir como parâmetro de estudo acerca desta política de austeridade adotada.

Acerca deste decreto-lei, inicialmente, observa-se que foi editado para atender a um acordo firmado entre o Governo de Portugal e alguns entes que objetivam tutelar a saúde econômica de países a eles aliados. Neste sentido, o Governo português assumiu o compromisso perante o Fundo Monetário Internacional (FMI), a Comissão Europeia (CE) e o Banco Central Europeu (BCE) de tomar medidas com o intuito de tornar o SNS sustentável, atuando para isso seja no regime geral de acesso ou no regime especial de benefícios, ou, até mesmo, sendo mais incisivo acerca dos recursos financeiros que mantém tal Sistema. Nessa perspectiva, para alcançar tal meta, adotou-se a medida de rever as taxas moderadoras do SNS (PORTUGAL, 2011).

Vale ressaltar que tais taxas são uma das maneiras pela qual o Sistema Nacional de Saúde mantém-se ativo, pois os usuários, de acordo com o caso concreto, precisarão de pagar certa quantia para obter atendimento público médico-hospitalar (Princípio do tendencialmente gratuito). Destarte, o decreto-lei em análise pretendeu manter a limitação do valor dessas taxas a um terço dos preços do SNS. Em relação aos demais valores, estes serão atualizados anualmente de acordo com a inflação existente à época. Outro ponto tratado foi sobre a diferenciação positiva dos usuários aos serviços primários de saúde, objetivando, com 
isso, incentivar tais cuidados (PORTUGAL, 2011).

Ademais, $\mathrm{o} \quad$ Decreto-Lei $\mathrm{n}^{\mathrm{o}} \quad 113$ (PORTUGAL, 2011) também tratou da isenção de pagamento das taxas moderadoras que de acordo com o texto da norma será "com base em critérios de racionalidade e de discriminação positiva dos mais carenciados e desfavorecidos, ao nível do risco de saúde ponderado e ao nível da insuficiência econômica comprovada." (PORTUGAL, 2011).

Com isso, o Governo português teve por intuito melhorar a efetividade das taxas moderadoras, por meio da adoção de procedimentos mais céleres e operacionalizando tal cobrança. Neste sentido, a Entidade Reguladora de Saúde (responsável pela fiscalização da prestação de saúde) determinou que a iniciativa privada priorizasse o pagamento por meio de taxas moderadoras, em detrimento do pagamento diferido, o que corrobora a ideia a ser difundida por meio deste decreto-lei (PORTUGAL, 2011).

É importante também evidenciar o intuito a ser atingido por este decreto, trazido na exposição de motivos do próprio Decreto-Lei:

Em concreto, a revisão do sistema de taxas moderadoras deverá ser perspectivada como uma medida catalisadora da racionalização de recursos e do controlo da despesa, ao invés de uma medida de incremento de receita, atendendo não apenas à sua diminuta contribuição nos proveitos do Serviço Nacional de Saúde mas, acima de tudo, pelo carácter estruturante que as mesmas assumem na gestão, via moderação, dos recursos disponíveis, que são, por definição, escassos (PORTUGAL, 2011).

Assim, tal norma pretendeu conceder maior eficiência aos gastos com saúde, pois a modificação na cobrança das taxas moderadoras, acarreta na redução dos infindáveis gastos públicos no setor, sem que pudesse gerar um consequente prejuízo na prestação do serviço público de saúde.

\section{CONCLUSÃO}

Este trabalho evidenciou que em Portugal o sistema de saúde é formado por um conjunto de ações não somente governamentais. Assim, o Sistema Nacional de Saúde é apenas o principal programa que objetiva efetivar as prestações em saúde pública para a população. Além disso, observou-se que, apesar do caráter elementar que este programa de assistência de saúde possui, não é totalmente gratuito, permitindo, apenas em alguns casos, a exclusão do pagamento das denominadas taxas moderadoras.

Diante da permissão constitucional da desnecessidade do oferecimento de serviços de saúde gratuitos para a população, o Governo português vem possibilitando que haja o crescimento da atuação do setor privado neste âmbito. Assim, a iniciativa privada vem avançando a sua atuação diante da abertura concedida pela Administração Pública. Dessa forma, o aumento do controle por parte do Governo, para fiscalizar as ações adotadas pelas empresas, a fim de manter o respeito aos princípios da universalidade e da generalidade, faz-se primordial.

Apesar de Portugal ainda sofrer consequências da crise econômica mundial iniciada em 2008, o Governo ainda tenta manter as prestações em saúde pública de maneira a respeitar os ditames constitucionais, uma vez que, por meio dos estudos de caso, observou-se que as ações governamentais têm o objetivo de manter as prestações de saúde pública de maneira satisfatória para a população, apesar da situação econômica pela qual perpassa o país não ser favorável para o custeio de ações que visem o despendimento financeiro para arcar com custear a efetivação do direito social à saúde.

Dessa forma, evidenciou-se que, por meio dos decretos-lei estudados, bem como diante da pesquisa de revisão de literatura realizada, Portugal, apesar das dificuldades financeiras em 
que se encontra, ainda adota políticas públicas que visam a manutenção de serviços de saúde pública à população, respeitando, com isso, os ditames constitucionalmente previstos de respeito aos princípios da universalidade, da generalidade e do caráter tendencialmente gratuito.

Além disso, devido ao fato de a efetivação do direito à saúde demandar vultosos gastos financeiros, o Governo vem permitindo $o$ crescimento da atuação do setor privado neste âmbito, o que permite a manutenção das prestações de saúde, apesar da escassez de recursos econômicos pela qual o Estado encontrase. Por outro lado, eleva a necessidade do Governo manter a fiscalização das ações adotadas por esses empresários, pois o que deve ser sempre respeitado são os ditames constitucionais, bem como deve-se objetivar o respeito à dignidade da pessoa humana.
Com efeito, este trabalho de caráter exploratório-descritivo, evidenciou uma realidade que vem perpassando um país que sofre consequências de uma recessão econômica que, apesar de ter decorrido quase 10 anos de seu início, ainda ocasiona problemas econômicos e sociais importantes. Assim, a análise do sistema de saúde português e sua inserção em um período de recuperação econômica é apenas um dos pontos a serem discutidos diante da efetivação de um direito essencial para o indivíduo, qual seja, o direito à saúde. Logo, um recorte mais pormenorizado deste sistema em um contexto de crise, bem como quais são as consequências que este período de recessão econômica acarretarão para as prestações de saúde pública em outro contexto econômico, também são importantes para melhor compreensão dos impactos da crise de 2008 no contexto da efetivação do direito à saúde em Portugal.

\section{REFERÊNCIAS}

A ECONOMIA de Portugal hoje. Mercados e Estratégias. Disponível em: <http://www.mercadoseestrategias.com/news/a-economia-de-portugal-hoje/>. Acesso em: 18 set. 2017.

ANDRADE, Andreia da Costa. A Regulação do Sistema de Saúdo Português: Contribuição para um novo paradigma na prestação de cuidados de saúde. e-Pública, Lisboa, v. 3, n. 3, p. 201-221, dez. 2016

Disponível em <http://www.scielo.mec.pt/scielo.php?script=sci_arttext\&pid=S2183184X2016000300010\&lng=pt\&nrm=iso>. Acesso em: 06 set. 2017.

BAGANHA, M.; RIBEIRO, J.; PIRES, S. O Sector da Saúde em Portugal: Funcionamento do Sistema e Caracterização Sócio-Profissional, Oficina do CES, 182, p. 1-33, 2002.

CAUSAS da crise na Europa (o problema fiscal e a enorme dívida pública) e as consequências (piora na relação dívida pública / PIB, reservas baixas e o aumento das taxas de desemprego). Em Discussão, Brasília, v. 16, n. 4, p. 22-24, jul. 2013. Disponível em: <https://www.senado.gov.br/noticias/Jornal/emdiscussao/contas-publicas/mundo/causas-da-crise-naeuropa-o-problema-fiscal-enorme-divida-publica-consequencias-reservas-baixas-o-aumento-dastaxas-de-desemprego-divida-publica-em-relacao-ao-pib.aspx>. Acesso em: 27 jul. 2017.

CANOTILHO, José Joaquim Gomes. Direito Constitucional e Teoria da Constituição. 7. ed. Coimbra: Almedina, 2003. 
CARVALHO, Pedro Walicoski. A saúde como direito do cidadão e dever do estado: consolidação pela via judicial.2013. 125 f. Dissertação (Mestrado) - Curso de Ciência Jurídica, Universidade do Vale do Itajaí - Univali, Itajaí, 2013.

CONSTITUCIONAL, XXI Governo. O Governo. Disponível em: <http://www.portugal.gov.pt/pt/ademocracia-portuguesa/o-governo/o-governo.aspx>. Acesso em: 02 ago. 2017.

CRISÓSTOMO, Sofia. O artigo 64. ${ }^{\circ}$ da Constituição da República Portuguesa: saúde. Sociologia, Problemas e Práticas, Lisboa, Portugal, número especial, p. 33-48, 2016.

MIRANDA, Jorge. A originalidade e as principais características da Constituição portuguesa. Cuestinoes Constitucionales, México, n. 16, p. 253-280, jun. 2007 . Disponível em <http://www.scielo.org.mx/scielo.php?script=sci_arttext\&pid=S1405-

$91932007000100008 \& \operatorname{lng}=\mathrm{es} \& \mathrm{nrm}=\mathrm{iso}>$. Acesso em: 06 set.2017

NOVAES, Jorge Reis. Direitos Sociais. Coimbra: Coimbra Editora, 2010.

SOUSA, Paulino Artur Ferreira de. O sistema de saúde em Portugal: realizações e desafios. Acta Paul Enferm, São Paulo, v. 22, p. 884-894, 2009.

PORTUGAL. Lei $N^{o}$ 56, 1979. Disponível em: <https://dre.pt/web/guest/pesquisa//search/369864/details/normal?p_p_auth=JqNc3epD>. Acesso em: 18 set. 2017.

Constituição (1976). Constituição da República Portuguesa. Disponível em: <http://www.parlamento.pt/Legislacao/Paginas/ConstituicaoRepublicaPortuguesa.aspx> Acesso em: 18 set.2017.

. Decreto-lei $\quad N^{o} \quad 11, \quad$ 1993. Disponível em: < https://www.sns.gov.pt/wpcontent/uploads/2016/04/Decreto-Lei-n.\%C2\%BA-1193.-DR-1293-SE\%CC\%81RIE-I-A-de-199301-15.pdf>. Acesso em: 18 set. 2017.

. Decreto-lei $N^{o}$ 69, 2013. Disponível em: <https://dre.tretas.org/dre/309296/decreto-lei-692013-de-17-de-maio>. Acesso em: 18 set. 2017.

. Decreto-lei $N^{o} 113,2011$. Disponível em: <https://dre.tretas.org/dre/287977/decreto-lei-1132011-de-29-de-novembro.>. Acesso em: 18.set. 2017.

RAIMUNDO, Miguel Assis. A administração da saúde em tempo de crise. In: A crise e o direito público VII encontro de professores portugueses de direito público, $n$. 6, 2013, Lisboa. Formato digital. Lisboa, Portugal: Instituto de Ciência Jurídico-Políticas, 2013. p. 133-168.

SERAPIONI, Mauro; SESMA, Dolores. A participação dos cidadãos nos sistemas de saúde dos países da Europa do Sul: Portugal, Itália e Espanha. Resultados preliminares de um estudo comparativo. Sociologia On Line. Revista da Associação Portuguesa de Sociologia, Coimbra, Portugal, v. 2, p.599-629, abr. 2011.

MINISTRO DA SAÚDE. SNS "é um dos mais eficientes da Europa". República Portuguesa XXI Governo Constitucional. Disponível em: <www.portugal.gov.pt/pt/ministerios/ms/noticias/20170427ms-sns.aspx>. Acesso em: 27 jul. 2017. 
UNIÃO EUROPEIA. Assuntos econômicos e monetários. Europa.eu. Disponível em: <https://europa.eu/european-union/topics/economic-monetary-affairs_pt>. Acesso em: 13 set. 2017.

Recebido em: 07/06/2018

Aceito em: 23/11/2018 
